\title{
Effects of Climate Change and Human Activities on Surface Runoff in the Luan River Basin
}

\author{
Sidong Zeng, ${ }^{1}$ Chesheng Zhan, ${ }^{2}$ Fubao Sun, ${ }^{2}$ Hong Du, ${ }^{3}$ and Feiyu Wang ${ }^{2}$ \\ ${ }^{1}$ Changjiang Institute of Survey, Planning, Design and Research, Changjiang Water Resources Commission, Wuhan 430010, China \\ ${ }^{2}$ Key Laboratory of Water Cycle and Related Land Surface Processes, The Institute of Geographic Sciences and \\ Natural Resources Research, CAS, Beijing 100101, China \\ ${ }^{3}$ College of Chemistry and Materials, South-Central University for Nationalities, Wuhan 430074, China
}

Correspondence should be addressed to Chesheng Zhan; zhancs@igsnrr.ac.cn

Received 28 November 2014; Accepted 4 February 2015

Academic Editor: Hiroyuki Hashiguchi

Copyright (C) 2015 Sidong Zeng et al. This is an open access article distributed under the Creative Commons Attribution License, which permits unrestricted use, distribution, and reproduction in any medium, provided the original work is properly cited.

\begin{abstract}
Quantifying the effects of climate change and human activities on runoff changes is the focus of climate change and hydrological research. This paper presents an integrated method employing the Budyko-based Fu model, hydrological modeling, and climate elasticity approaches to separate the effects of the two driving factors on surface runoff in the Luan River basin, China. The Budykobased Fu model and the double mass curve method are used to analyze runoff changes during the period 1958 2009. Then two types of hydrological models (the distributed Soil and Water Assessment Tool model and the lumped SIMHYD model) and seven climate elasticity methods (including a nonparametric method and six Budyko-based methods) are applied to estimate the contributions of climate change and human activities to runoff change. The results show that all quantification methods are effective, and the results obtained by the nine methods are generally consistent. During the study period, the effects of climate change on runoff change accounted for $28.3 \sim 46.8 \%$ while those of human activities contributed with 53.2 71.7\%, indicating that both factors have significant effects on the runoff decline in the basin, and that the effects of human activities are relatively stronger than those of climate change.
\end{abstract}

\section{Introduction}

The water cycle is subjected to the dual influences of both climate change and human activities [1]. Climate change, especially the change of rainfall and temperature, will largely determine the future runoff of a basin [2]. Human activities such as land use and cover change (LUCC) [3] and water resources projects [4] will also affect the water resources. Hence, it is important to separate the effects of climate change and human activities on runoff changes in order to identify the leading factors and to develop sustainable water resources management strategies in a changing environment. To date, several studies have been attempted to separate the effects of climate change and human activities. For example, Wang et al. [2] analyzed the effects of climate change and human activities on runoff in two basins in northern China using a monthly water balance model and fixing-changing method and showed that the effects of human activities (accounting for $65 \%$ and $69 \%$, resp.) are stronger than those of climate change (accounting for $35 \%$ and $31 \%$, resp.) in the two basins. Zhang et al. [5] concluded that the effects of climate change on annual runoff reduction accounted for about $43 \%$ according to the Budyko-based Fu model applied to the HunTai River basin in China. Li et al. [6] found that the land use change effects contributed with about $31 \sim 40 \%$ to runoff decline when using both hydrological models and sensitivitybased approaches in three catchments in southeast Australia. These studies together show that the effects of climate change and human activities on runoff vary between different basins, and regional analysis of the local-scale effects needs to be considered, particularly for the basins with intensive human activities where more aspects related to hydrological cycle should be considered.

Present studies mainly follow the paradigm of "determining the abrupt change points and baseline period, and then quantifying the effects of climate change and human 
activities." Firstly, statistical methods (e.g., nonparametric tests and time series analysis) and graphical methods (e.g., double mass curve and flow duration curves) are often used to detect the change points of runoff changes [7]. Secondly, the hydrological modeling approach $[8,9]$ and climate elasticity approach $[10,11]$ are used to quantify the effects of climate change and human activities on runoff changes. Usually, the hydrological modeling approach is used to measure the effects using physically based distributed hydrological models or lumped conceptual models. The lumped conceptual models are often easier to calibrate and use fewer input datasets, while the distributed hydrological models are difficult to apply to large basins due to their requirement of more detailed inputs. However, the distributed hydrological models could provide more details of the hydrological cycle with respect to different spatial patterns. Compared to the hydrological modeling approach, the climate elasticity approach is another useful method using fewer hydroclimatic datasets; however, climate elasticity methods are usually based on annual means and so provide generalized relationships without considering the underlying surface of a basin [6]. Two common types of climate elasticity approaches are the statistical analysis-based nonparametric method [12] and the Budyko-based analytical derivation method $[13,14]$. A comparison of the two types may help to improve and extend the climate elasticity methods. In general, integrating the hydrological modeling and climate elasticity approaches will be better for understanding the complex relationships between climate change, human activities, and the water cycle. Thus, this paper presents an integrated method based on the Budyko-based Fu model, hydrological modeling, and climate elasticity approaches to quantify the effects of climate change and human activities on surface runoff. Moreover, the two approaches (hydrological modeling and climate elasticity methods) are also discussed in terms of the uncertainties and the influencing factors of the quantitative results, whereas few previous studies have conducted these analyses.

The Luan River basin is one of the most vulnerable areas to intensive human activities and climate change in China [15]. It is also the main water source of some big cities in northern China. Fan et al. [16] found that reduced streamflow is mainly an impact of precipitation change. However, Wang and Liu [17] found that the reduced water resources are mainly due to the impacts of human activities, including irrigation and water diversion. The studies found different conclusions, yet quantitative research distinguishing the influences of climate change and human activities on the water cycle in this basin remains scarce. Therefore, we tried to conduct a systemic study on this topic in the basin using longterm datasets covering 1958-2009 and found an efficient and practical approach to separate the effects of climate change and human activities.

The objective of this study is to quantify the influence of climate change and human activities on runoff in the Luan River basin using an integrated method combing a climate elasticity approach (using one nonparametric method and six Budyko-based methods) with a hydrological modeling approach (the Soil and Water Assessment Tool (SWAT) distributed model and SIMHYD lumped model). In addition,

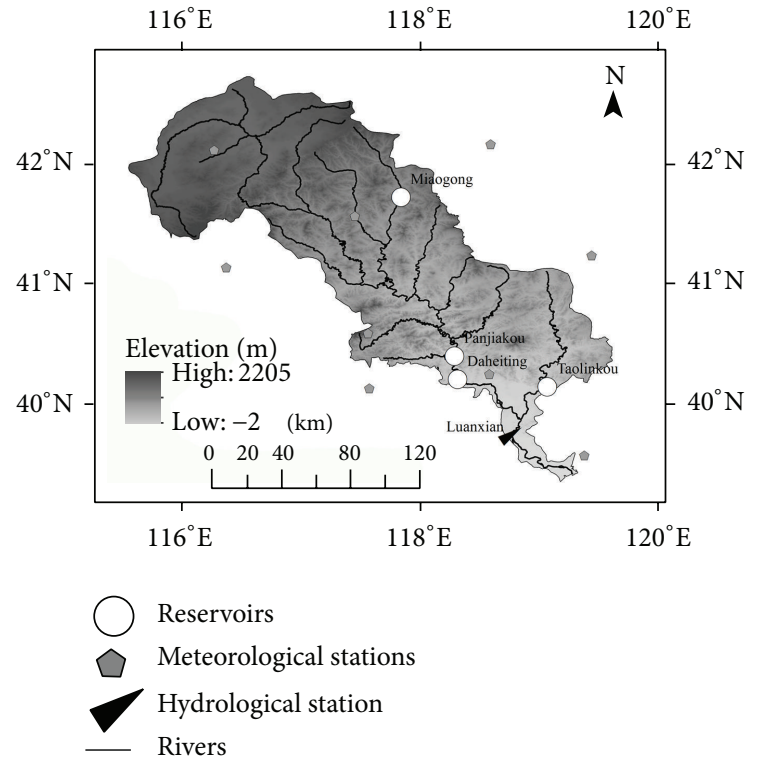

FIGURE 1: Location of the Luan River basin with meteorological and hydrological stations and reservoirs.

the two approaches used for the quantification are also discussed and analyzed. The paper is arranged as follows. Section 2 describes the characteristics of the study basin and data sources used. Section 3 describes the methodology including the Fu model for the abrupt change point detection, the structures of the SIMHYD and SWAT models, the hydrological model calibration and validation, details of the climate elasticity methods, and methodology for separating the effects of climate change and human activities. Results are provided and discussed in Section 4 and conclusions are summarized in Section 5.

\section{Study Area and Data}

The Luan River basin (LRB), shown in Figure 1, is located in the region $115.5^{\circ} \mathrm{E} \sim 119.3^{\circ} \mathrm{E}, 39.2^{\circ} \mathrm{N} \sim 42.5^{\circ} \mathrm{N}$ in North China, and covers an area of $44,750 \mathrm{~km}^{2}$. The basin lies in the temperate continental monsoon zone with a hot and rainy summer, dry and rainless spring and autumn, and dry and cold winter. From 1958 to 2009 the average annual precipitation was $491 \mathrm{~mm}$ and the average annual temperature was $6.9^{\circ} \mathrm{C}$. Since the 1980s, several large reservoirs including Miaogong Reservoir, Daheiting Reservoir, Panjiakou Reservoir, and Taolinkou Reservoir were built (Figure 1), and some water diversion projects were also constructed to supply water to Tianjin and Tangshan cities and for irrigation in the Luanxian Irrigation Area.

Data used in this study consist of daily precipitation, maximum and minimum temperature, and sunshine duration at nine meteorological stations from 1958 to 2009 supplied by the China Meteorological Data Sharing Service System. Monthly runoff data covering the same period were obtained for the Luanxian gauge station (Figure 1). The Luanxian gauge station is located in the lower reaches of the basin and 
its hydrological characteristics represent the characteristics of the whole basin. Daily potential evapotranspiration data needed for hydrological modeling were calculated by the Hargreaves method [18], which has been validated in this region [19].

The digital geographic information data applied in the distributed hydrological modeling including digital elevation model (DEM) data at $500 \mathrm{~m}$ resolution are from the public domain of GTOPO 30 of the American Geological Survey, and the land use and soil type data are from the resources and environment data center of the Chinese Academy of Sciences at $1000 \mathrm{~m}$ resolution.

\section{Methods}

3.1. Detection of the Abrupt Change Point. According to the Budyko $[20,21]$ hypothesis, there exists a water-heat coupling balance relationship between the water and energy in a basin, for which $\mathrm{Fu}$ [22] developed the following equation:

$$
\frac{E}{P}=1+\frac{E_{0}}{P}-\left[1+\left(\frac{E_{0}}{P}\right)^{w}\right]^{1 / w},
$$

where $P, E$, and $E_{0}$ represent the average annual precipitation, actual evapotranspiration, and potential evapotranspiration, respectively; $w$ is the model parameter, which has little correlation with the area of a certain basin but has a close relationship with the properties of the underlying surface, including the soil infiltration capability, plant-soil relative water demand capability, mean slope of the basin [23], and the runoff coefficient [24]. Also $w$ has a dependency on the climatic properties of the watershed and the interaction between the climate and the hydrological response in a basin [25]. Therefore the parameter $w$ can be used to represent the characteristics of the water cycle in a basin.

This study uses the 5-year moving averages of precipitation and of actual and potential evapotranspiration as the input to (1). In addition, the 5-year average actual evapotranspiration is calculated by the water balance equation based on the presumption that soil water content remains stable within a 5-year period [26]. With the results of $w$ based on (1), the abrupt change point due to the effects of human activities can be identified by the Mann-Kendall test [27, 28].

\subsection{Framework of Separating the Effects of Climate Change} and Human Activities. In this study, the human activities effects refer to the total influence of land use and cover change and water diversion for irrigation and industrial and domestic usage. The climate change effects refer to the total influence by the precipitation, temperature, or potential evapotranspiration changes. The total changes in mean annual runoff between two periods with different human activities and climate characteristics can be estimated by the following equation:

$$
\Delta Q=\overline{Q_{\text {obs }}^{\text {test }}}-\overline{Q_{\text {obs }}^{\text {pre }}}
$$

where $\Delta Q$ is the difference in annual average runoff. $\overline{Q_{\text {obs }}^{\text {pre }}}$ and $\overline{Q_{\text {obs }}^{\text {test }}}$ are the mean annual measured runoff during the pretreatment period and the testing period, respectively; the period is divided by the abrupt change point identified in Section 3.1. For a given catchment, the total runoff change between the two periods can also be described as follows, when considering climate change and human activities as independent variables at the basin scale [2]:

$$
\Delta Q=\Delta Q_{C}+\Delta Q_{H}
$$

where $\Delta Q_{C}$ is the average runoff change due to the climate change and $\Delta Q_{H}$ is the runoff change due to human activities. Sections 3.3 and 3.4 provide the details for estimating $\Delta Q_{C}$ and $\Delta Q_{H}$ using the hydrological modeling approach and climate elasticity approach, respectively.

3.3. Hydrological Modeling Approach. In view of the uncertainties associated with the model structure, parameter calibration, and scale change, we select two kinds of hydrological models, the SIMHYD lumped model and the SWAT distributed model. The hydrological model is calibrated and validated in the pretreatment period and then used to simulate the hydrological processes in the testing period. The difference between simulated runoff and observed runoff in the testing period is used to quantify the impact of human activities as follows:

$$
\Delta Q_{H}=\overline{Q_{\mathrm{obs}}^{\text {test }}}-\overline{Q_{\text {sim }}^{\text {test }}},
$$

where $\overline{Q_{\text {sim }}^{\text {test }}}$ and $\overline{Q_{\text {obs }}^{\text {test }}}$ are the average simulated and observed annual runoff for the testing period, respectively. The impact of climate change can be quantified via (3).

The SIMHYD model is a lumped hydrological model developed by Chiew et al. [29], which is simple but useful and has been tested in China [30]. In SIMHYD, evapotranspiration is calculated based on the potential evapotranspiration constrained by available soil moisture. Runoff generation is estimated from three sources: infiltration excess runoff, interflow (saturation excess runoff), and base flow. The inputs of this model are the daily precipitation and potential evapotranspiration.

The SWAT model is a management model for large and medium-size basins developed by the American Agricultural Ministry [31]. In this study, the SWAT version 2005 is used. The SCS curve method is adopted to calculate runoff for the daily meteorological data available and the Penman-Monteith Equation is used to calculate the potential evapotranspiration. Similar studies have confirmed the applicability of the SWAT model in the Luan River basin [32]. The inputs to this model include both meteorological datasets and the digital geographic information datasets.

The Shuffled Complex Evolution Method (SCE-UA) [33] is used to calibrate the parameters by maximizing the NashSutcliffe efficiency coefficient (NS) [34] for both models. The NS, relative error (RE), and correlation coefficient $(r)$ are selected as the model performance indicators.

3.4. Climate Elasticity Approach. Schaake [35] firstly employed the climate elasticity method to analyze the sensitivity of runoff to climate change. The runoff elasticity is defined 
TABLE 1: Six commonly used forms based on Budyko hypothesis.

\begin{tabular}{lcc}
\hline & $F(\phi)$ & $F^{\prime}(\phi)$ \\
\hline Schreiber, 1904 [36] & $1-e^{-\phi}$ & $e^{-\phi}$ \\
Ol'dekop, 1911 [37] & $\phi \tanh (1 / \phi)$ & $\tanh (1 / \phi)-4 /\left[\phi\left(e^{-1 / \phi}+e^{1 / \phi}\right)^{2}\right]$ \\
Budyko, $1948[20]$ & $0.5\left[\phi \tanh (1 / \phi)\left(1-e^{-\phi}\right)\right]^{-0.5} \times$ \\
Pike, 1964 [38] & $\left(1+\phi^{-2}\right)^{-0.5}$ & {$\left[\left(\tanh (1 / \phi)-\operatorname{sech}^{2}(1 / \phi) / \phi\right)\left(1-e^{-\phi}\right)+\phi \tanh (1 / \phi) e^{-\phi}\right]$} \\
Fu, 1981 [22] & $1+\phi-\left(1+\phi^{\alpha}\right)^{1 / \alpha}$ & $1 /\left[\phi^{3}\left(1+(1 / \phi)^{2}\right)^{1.5}\right]$ \\
Zhang et al., 2001 [39] & $(1+w \phi) /(1+w \phi+1 / \phi)$ & $1-\left(1+\phi^{\alpha}\right)^{1 / \alpha-1} \phi^{\alpha-1}$
\end{tabular}

The parameters $\alpha$ and $w$ in the Fu and Zhang method should be calibrated firstly.

as the ratio of the runoff variation rate to the variation rate of a certain climate factor as follows:

$$
\varepsilon_{X}=\frac{\partial Q / Q}{\partial X / X} \text {, namely: } \frac{\partial Q}{\partial X}=\varepsilon_{X} \frac{Q}{X} \text {. }
$$

Based on the assumption that the response of runoff to the climate factors is mainly caused by precipitation and potential evapotranspiration, we can obtain the following equation [10]:

$$
\Delta Q_{C}=\varepsilon_{P} \frac{Q}{P} \Delta P+\varepsilon_{E_{0}} \frac{Q}{E_{0}} \Delta E_{0},
$$

where $\Delta P$ and $\Delta E_{0}$ are the variation of precipitation and potential evapotranspiration, and $\varepsilon_{P}$ and $\varepsilon_{E_{0}}$ are the runoff elasticity to precipitation and potential evapotranspiration, respectively. By calculating $\Delta Q_{C}$, the effects of climate change and human activities can be separated. $\varepsilon_{P}$ and $\varepsilon_{E_{0}}$ need to be estimated firstly. Sections 3.4.1 and 3.4.2 describe the nonparametric method and Budyko-based methods to estimate the climate elasticity coefficients.

3.4.1. Nonparametric Method. Sankarasubramanian et al. [12] developed a nonparametric method to estimate $\varepsilon_{P}$, and the method has been validated in China [40]:

$$
\varepsilon_{P}=\operatorname{median}\left(\frac{\left(Q_{i}-\bar{Q}\right) / \bar{Q}}{\left(P_{i}-\bar{P}\right) / \bar{P}}\right),
$$

where $Q_{i}, P_{i}$ are the annual runoff and precipitation and $\bar{Q}, \bar{P}$ are the average annual runoff and precipitation.

3.4.2. Budyko-Based Methods. Based on the water balance equation and the Budyko coupling balance theory, we can obtain the following equation $[13,41]$ :

$$
\varepsilon_{P}=1+\frac{\phi F^{\prime}(\phi)}{1-F(\phi)}, \quad \varepsilon_{P}+\varepsilon_{E_{0}}=1,
$$

where the aridity index $\phi=E_{0} / P$ and six commonly used forms of the Budyko hypothesis $[13,42]$ adopted in this study are showed in Table 1.

\section{Results}

4.1. Abrupt Change Point Analysis. In this study, the Fu model based on the Budyko hypothesis and the Mann-Kendall (MK) test are used to detect the abrupt change point in the LRB using data covering 1958 2009. First, the values of $w$ in the $\mathrm{Fu}$ model are calculated based on (1) using observed precipitation, calculated potential evapotranspiration by Hargreaves method, and actual evapotranspiration obtained from the water balance, as shown in Figure 2(a). The actual evapotranspiration, which is important for the application of (1), should be validated first. The average annual actual evapotranspiration is about $400 \mathrm{~mm}$ and shows a slight increasing trend from 1958 to 2009, which is similar to the results obtained by $\mathrm{Xu}$ and Yang [43]. Figure 2(a) shows that $w$ varied markedly in the range 2.0 to 4.7 from 1958 to 2009 and then increased abruptly in the late 1990s. The MK test is employed to analyze the change point of the $w$ series. Yue and Wang [44] found that the MK test result is distinct from the influence of time series autocorrelation when the significance level is greater than $95 \%$. Therefore, we analyze the change point after excluding the series autocorrelation. The results show that the change point in $w$ occurred in 1999 (Figure 2(b)). Furthermore, the double mass curve analysis (the curve of the relationship between accumulated annual observed runoff (RA) and precipitation (PA)), which is frequently used to detect hydrological changes caused by human activities [45], is also used to detect whether there is a change point of the water cycle, as shown in Figure 3. The predicted lines (I and II) show the slopes between RA and PA changed in 1999 from 0.194 before 1999 to 0.027 after 1999. Consistent with the results above, we can conclude that the influction point occurred in 1999; that is, the pretreatment period is 1958-1998 and the testing period is 1999-2009.

In this work, time series analysis is also used to estimate the variation of annual runoff, precipitation, and potential evapotranspiration (PET), as shown in Figure 4. The results show a slight decreasing trend in PET $(-0.51)$ and precipitation $(-1.25)$ and a relatively stronger decreasing trend in runoff (-2.04). In addition, compared with the pretreatment period, the reductions were $62.61 \mathrm{~mm}, 15.06 \mathrm{~mm}$, and $87.30 \mathrm{~mm}$ for precipitation, PET, and runoff, respectively, in the testing period. The corresponding changing ratios were $-12.4 \%,-1.70 \%$, and $-84.5 \%$ (see Table 2 ). These values show 


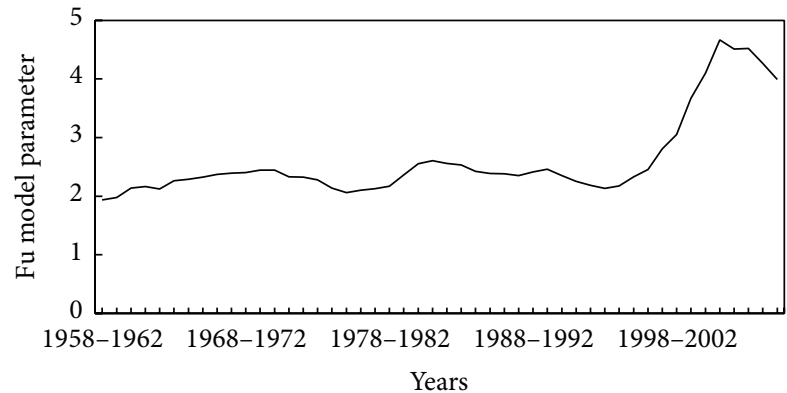

- Fu model parameter

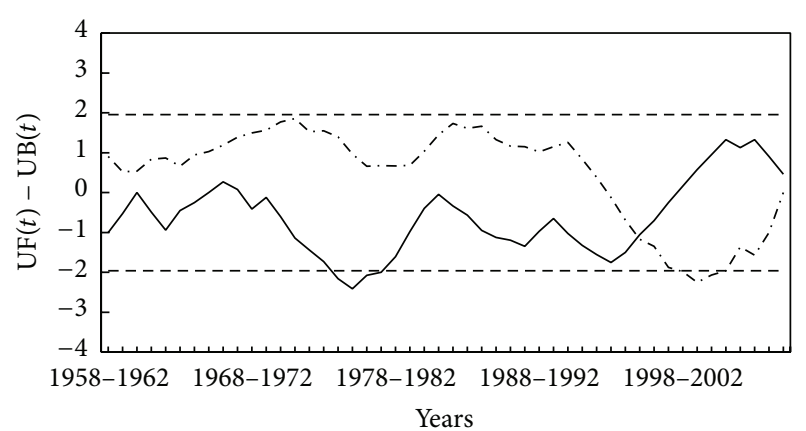

(b)

FIgURE 2: Variations of $w$ from 1958 to 2009 (a) and the UF (forward trend-solid line), UB (backward trend-dash dotted line) curves by Mann-Kendall test for $w$ and the 95\% confidence level line (dashed horizontal line) (b).

TABLE 2: The Mann-Kendall test statics slope $\left(Z_{c}\right)$ and changes of annual precipitation, potential evapotranspiration (PET), and observed runoff during the pretreatment period and testing period.

\begin{tabular}{lccccc}
\hline & $Z_{c}$ & Pretreatment period $(\mathrm{mm})$ & Testing period $(\mathrm{mm})$ & Difference $(\mathrm{mm})$ & Ratio $(\%)$ \\
\hline Precipitation & -1.26 & 504.61 & 442.00 & -62.61 & -12.40 \\
PET & -1.79 & 886.40 & 871.34 & -15.06 & -1.70 \\
Observed runoff & -2.29 & 103.31 & 16.01 & -87.30 & -84.50 \\
\hline
\end{tabular}

In a two-side test, when $-Z_{1-\alpha / 2} \leq Z_{c} \leq Z_{1-\alpha / 2}$ accepts a null hypothesis, or when $Z_{c}<-Z_{1-\alpha / 2}$ indicates a decreasing trend, and when $Z_{c}>Z_{1-\alpha / 2}$ indicates an increasing trend, $\alpha$ is the significance level. In this study, $\alpha$ is set to be 0.05 and the corresponding value of $Z_{1-\alpha / 2}$ is 1.96 [27, 28].

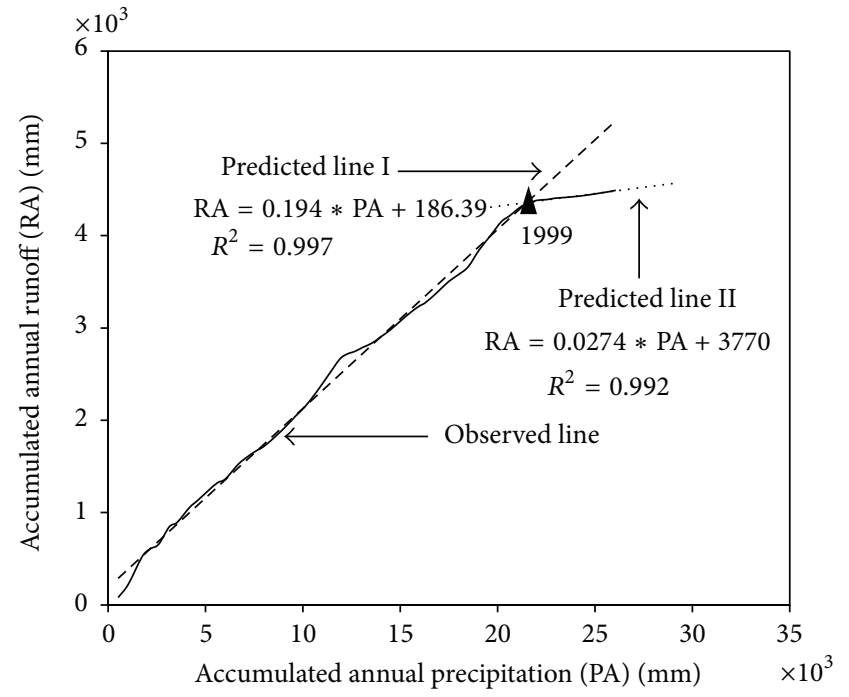

Figure 3: Double mass curve of accumulated annual runoff (RA) and accumulated annual precipitation (PA).

that the variation ratio of average annual runoff was much larger than that of precipitation and PET. Table 2 also provides the trend results of annual runoff, precipitation, and PET based on the MK test, which indicate that annual runoff decreased significantly ( $\alpha=0.05, \alpha$ is the significance level) with an MK statistics slope of -2.29 , while the annual precipitation and PET showed no significant decreasing trends $(\alpha=0.05)$. The results above suggest that the reduction of runoff was not caused solely by the reduction in precipitation and PET, so human activities may also have had an important impact on the runoff decline.

\subsection{Hydrological Modeling}

4.2.1. Model Performance. The SWAT and SIMHYD models are applied to simulate the hydrological processes in the LRB. First, two-thirds of the observed data are used to calibrate the two models and the calibrated parameters are used to simulate the streamflow for the remaining one-third of the observed data in the pretreatment period for model validations. It should be noted that the two hydrological models do not simulate the reservoirs in the calibration and validation for the human activities is limited in this period.

Results of the model calibration and validation at monthly time steps for the two models are shown in Figure 5. In the scatter plots in Figure 5, the observed monthly streamflow is plotted along the $x$-axis and the simulated streamflow is plotted along the $y$-axis. Figure 5 shows that both models perform well in model calibration and validation with high Nash-Sutcliffe efficiency coefficient (NS), correlation coefficient $(r)$ values, and low relative error (RE) values, as also shown in Table 3. The calibration NS values are $82 \%$ and $85 \%$ for the SWAT model and the SIMHYD model, respectively. The RE values are 0.05 and 0.07 for the two models, and the $r$ values are 0.91 and 0.92 in the calibration period. In the validation period, the NS, RE, and $r$ values are $92 \%, 0.003$, and 0.95 for the SWAT model and $90 \%, 0.02$, and 0.96 for the SIMHYD model, respectively. 


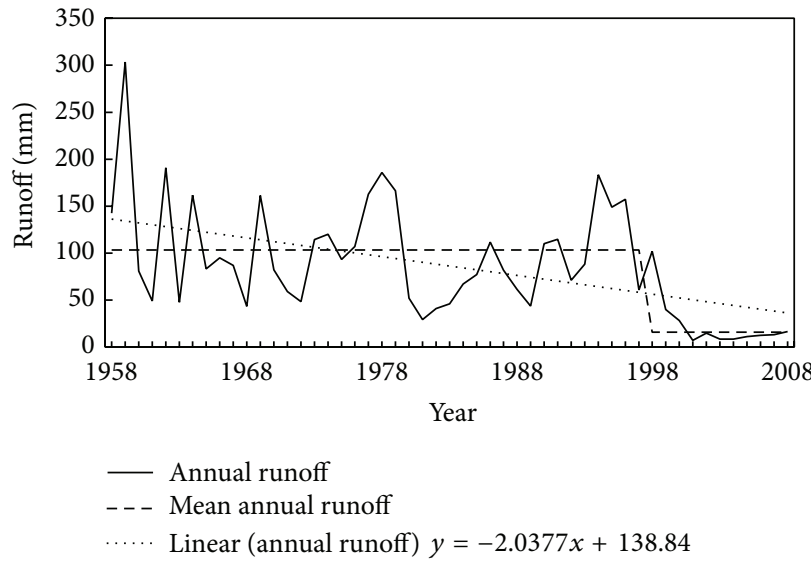

(a)

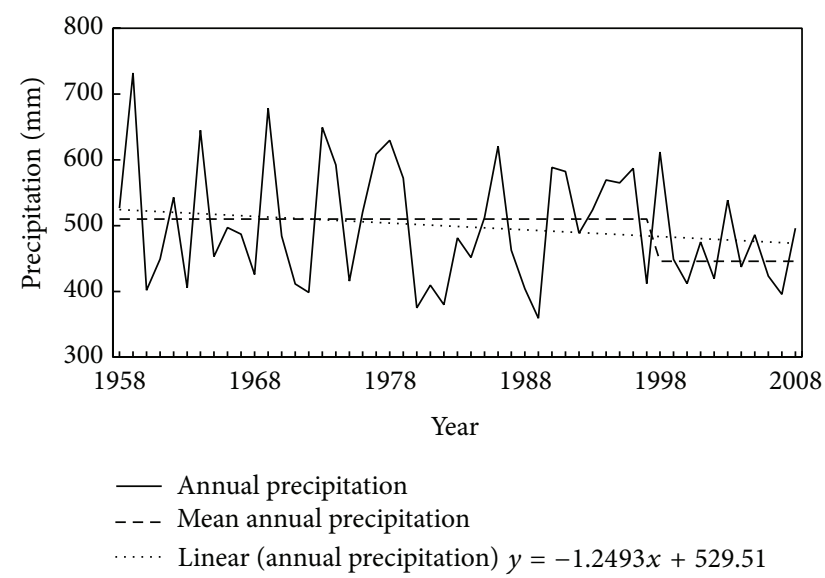

(b)

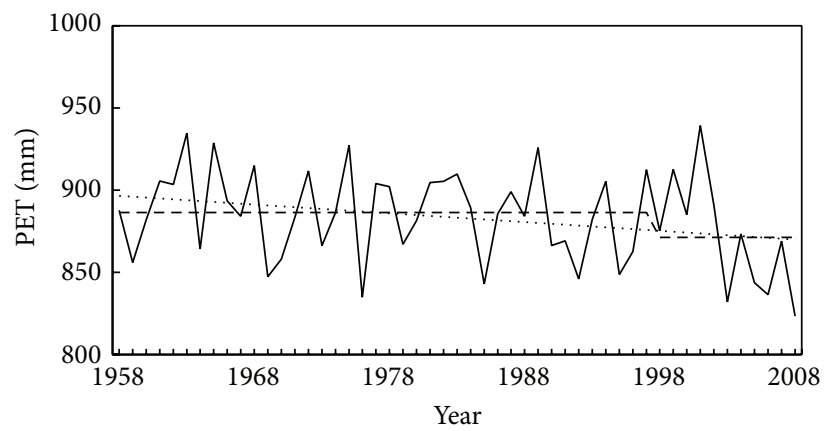

- Annual PET
- -
Mean annual PET
… Linear (annual PET) $y=-0.5142 x+896.84$

(c)

FIGURE 4: Variations of annual runoff (a), precipitation (b), and potential evapotranspiration (PET) (c) before and after inflection point (solid line), the average annual values (dashed line), and the linear trend (dotted line).

TABLE 3: The performance of SWAT model and SIMHYD model.

\begin{tabular}{|c|c|c|c|c|c|c|c|c|c|c|}
\hline & \multicolumn{5}{|c|}{ Calibration (1958-1985) } & \multicolumn{5}{|c|}{ Validation (1986-1998) } \\
\hline & NS & $\mathrm{RE}$ & $r$ & AWBE & AWED & NS & $\mathrm{RE}$ & $r$ & AWBE & AWED \\
\hline SWAT & 0.82 & 0.05 & 0.91 & 0.05 & 0.14 & 0.92 & 0.003 & 0.95 & 0.03 & 0.02 \\
\hline SIMHYD & 0.85 & 0.07 & 0.92 & 0.10 & 0.08 & 0.90 & 0.02 & 0.96 & 0.08 & 0.15 \\
\hline
\end{tabular}

As discussed above, the difference between average annual simulated runoff and observed runoff in the testing period represents the impact of human activities. The water balance error between annual observed runoff and annual simulated runoff (AWBE) will impact the quantitative results. From the statistical results in Table 3, the values of AWBE are 0.05 and 0.10 in the calibration period and 0.03 and 0.08 in the validation period for the SWAT and SIMHYD models, respectively; that is, the errors are acceptable for the two models and they perform well for annual runoff simulation. From Figures 5 and 6 , we can see that the simulated streamflow is much greater than the observed streamflow in the testing period. Therefore, it is necessary to examine the water balance error between annual observed runoff and simulated runoff in the dry periods (AWED) in the pretreatment period. We select the dry years (at a guaranteed rate of 75\%) to test the two models. As shown in Table 3, the AWED values are 0.14 and 0.08 in the calibration period and 0.02 and 0.15 in the validation period for the SWAT model and the SIMHYD model, respectively. These results indicate that the two models perform well and there are no systemic errors in the simulation of annual runoff in the dry periods, which can be regarded as a scientific basis for distinguishing the influences of climate change and human activities.

\subsection{Quantifying the Effects of Climate Change and Human} Activities. The SWAT and SIMHYD models are used to simulate the hydrological processes in the LRB during the testing period, based on the calibrated parameters in 

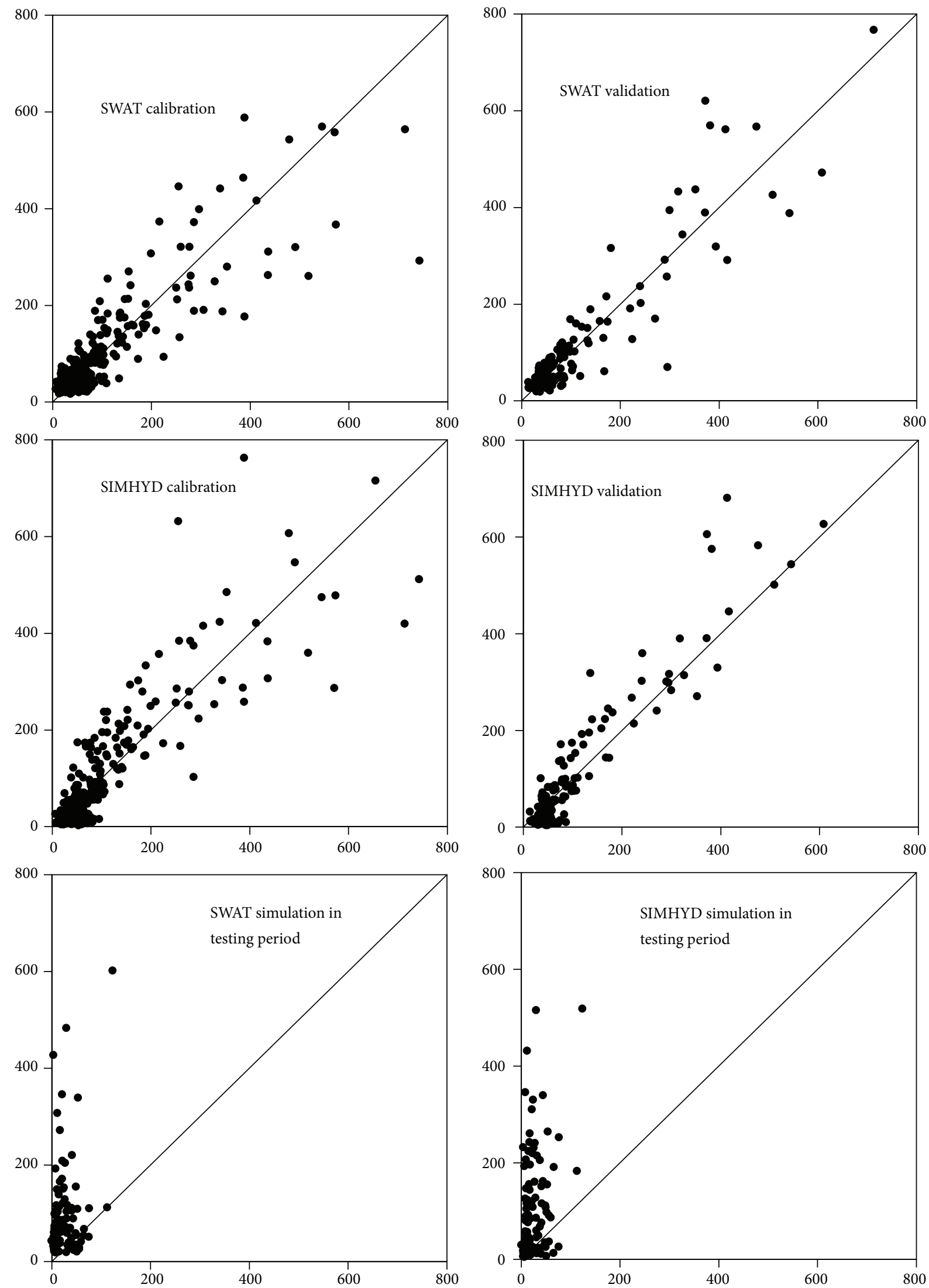

FIGURE 5: Comparison of observed and simulated monthly streamflow in calibration and validation periods and the testing period $\mathrm{m}^{3} / \mathrm{s}$. 


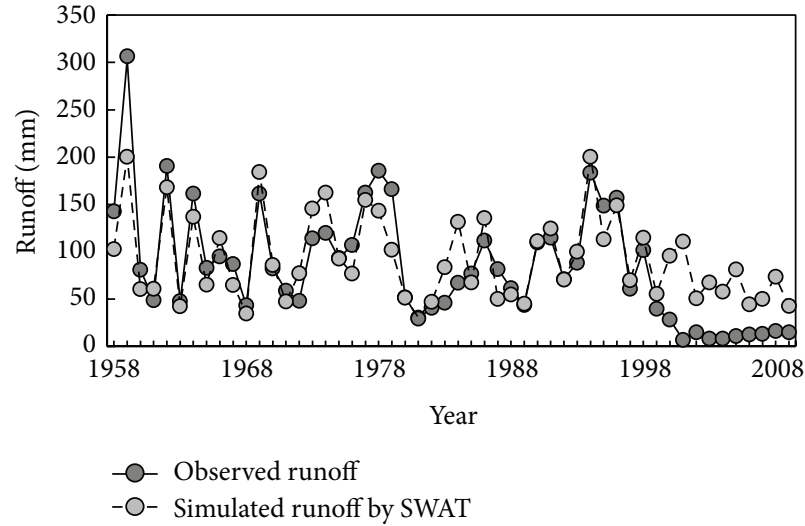

(a)

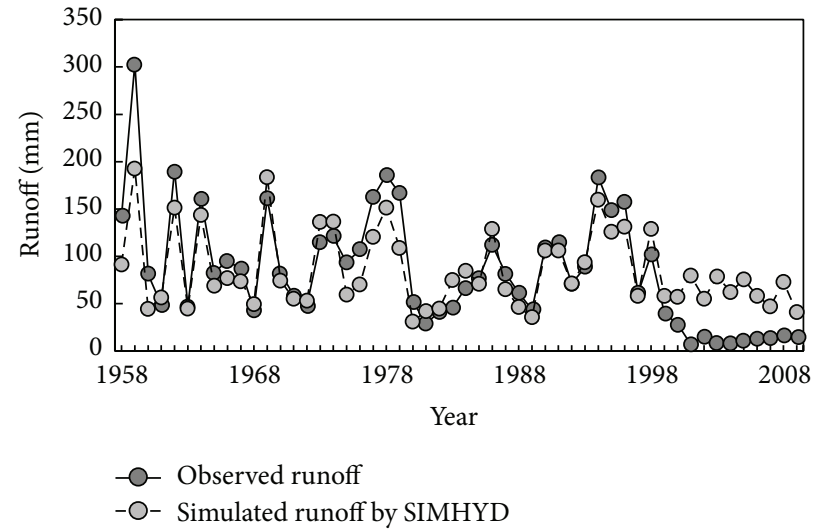

(b)

FIGURE 6: Comparison of observed annual runoff and simulated annual runoff by the SWAT (a) and SIMHYD (b) models.

TABLE 4: The average annual simulated and observed runoff during the pretreatment and testing periods (unit: $\mathrm{mm}$ ).

\begin{tabular}{lccc}
\hline Periods & $\begin{array}{c}\text { Observed } \\
\text { runoff }\end{array}$ & $\begin{array}{c}\text { Simulated by } \\
\text { SWAT }\end{array}$ & $\begin{array}{c}\text { Simulated } \\
\text { by SIMHYD }\end{array}$ \\
\hline Pretreatment period & 103.31 & 99.54 & 91.59 \\
Testing period & 16.01 & 66.57 & 62.45 \\
\hline
\end{tabular}

the pretreatment periods. The scatter plots in Figure 5 (the third column) and Figure 6 show a great difference between observed streamflow and simulated streamflow at monthly and yearly time steps in the testing period. Table 4 provides the statistical values of observed and simulated runoff in the pretreatment and testing periods. We can see that the simulated annual runoff after the change point is much greater than the observed annual runoff.

As stated previously, the difference between the average observed and simulated runoff reflects the influence of human activities. Meanwhile, the difference in the observed runoff between the testing period and the pretreatment period represents the total influence of climate change and human activities. Therefore, the effects of climate change can be obtained by calculating the difference between total influence and human activities influence. Results presented in Table 5 show the total difference caused by climate change and human activities is $87.3 \mathrm{~mm}$. The reduction runoff caused by human activities is $50.56 \mathrm{~mm}$ and $46.44 \mathrm{~mm}$ based on the SWAT and SIMHYD models, respectively. The runoff reduction caused by climate change was $36.74 \mathrm{~mm}$ and $40.86 \mathrm{~mm}$ based on the two models. The influence of human activities on the runoff accounted for $57.9 \%$ and the influence of climate change accounted for up to $42.1 \%$ according to the SWAT model. According to the SIMHYD model, human activities accounted for $53.2 \%$ of runoff decrease and the influence of climate change accounted for up to $46.8 \%$.

4.4. Climate Elasticity Analysis. The Fu and Zhang methods should be calibrated with the average annual observed runoff during the pretreatment period firstly. The parameter is 2.3 in the Fu method and 0.8 in the Zhang method. The simulated average annual runoff is $95.7 \mathrm{~mm}$ with the relative values of $7.33 \%$ by Fu method and $93.8 \mathrm{~mm}$ with the relative values of $9.25 \%$ by Zhang method during the pretreatment period, respectively. Then the climate elasticity of runoff to precipitation in the basin is calculated by the nonparametric method and six Budyko-based methods. From the results in Table 6, we can see that there are some differences among the seven methods for estimating the elasticity coefficients varying from 2.078 to 2.849 .

Based on (5), the impacts of climate change on runoff are quantified as shown in Table 6. The results indicate that the influence of climate change accounted for $28.3 \sim 38.1 \%$ of the runoff reduction, equivalent to about $29.9 \mathrm{~mm}$ reduction in runoff, while the contribution of human activities was 61.9 $71.7 \%$.

\section{Discussion}

The compared results by the two approaches including nine methods in Figure 7 show that the runoff reduction caused by climate change was $28.3 \sim 46.8 \%$, and the corresponding contribution due to human activities was $53.2 \sim 71.7 \%$. The results indicate that the effect of human activities was stronger than that of climate change. This finding agrees with the previous studies [46]. As described earlier, runoff showed a remarkable decreasing trend even though precipitation and PET presented no significant trends, thereby indicating that human activities may be the driving factors for runoff decline. Water-related human activities including land use and cover change and water diversion for irrigation and industrial and domestic water use are considered to be responsible for the runoff decline.

Statistics shows that the forest cover has decreased by $8 \%$ in the LRB since the mid-1990s, and the reduction in forest cover usually results in an increase in runoff [ 47 , 48]. However, the observed runoff in the LRB has shown a decreasing trend in the past years; this may be related 
TABLE 5: Quantification of the impact of climate change (CC) and human activities (HA) on runoff based on hydrological modeling.

\begin{tabular}{lccccc}
\hline Model & $\begin{array}{c}\text { Total difference } \\
(\mathrm{mm})\end{array}$ & $\begin{array}{c}\text { Runoff decline caused } \\
\text { by CC }(\mathrm{mm})\end{array}$ & $\begin{array}{c}\text { Runoff decline caused } \\
\text { by HA }(\mathrm{mm})\end{array}$ & $\begin{array}{c}\text { Percentage of } \\
\text { influence of CC }\end{array}$ & $\begin{array}{c}\text { Percentage of } \\
\text { influence of HA }\end{array}$ \\
\hline SWAT & 87.30 & 36.74 & 50.56 & $42.1 \%$ & $57.9 \%$ \\
SIMHYD & & 40.86 & 46.44 & $46.8 \%$ & $53.2 \%$ \\
\hline
\end{tabular}

TABLE 6: Quantification of the impacts of climate change based on climate elasticity methods.

\begin{tabular}{lccccccc}
\hline Climate change Impact & Nonparametric & Schreiber & Ol'dekop & Budyko & Pike & Fu & Zhang et al. \\
\hline$\varepsilon_{P}$ & 2.849 & 2.797 & 2.780 & 2.804 & 2.637 & 2.158 & 2.078 \\
Decline $(\mathrm{mm})$ & -33.27 & -32.70 & -32.51 & -32.78 & -30.93 & -25.64 & -24.75 \\
Percentage (\%) & 38.1 & 37.5 & 37.2 & 37.5 & 35.4 & 29.4 & 28.3 \\
\hline
\end{tabular}

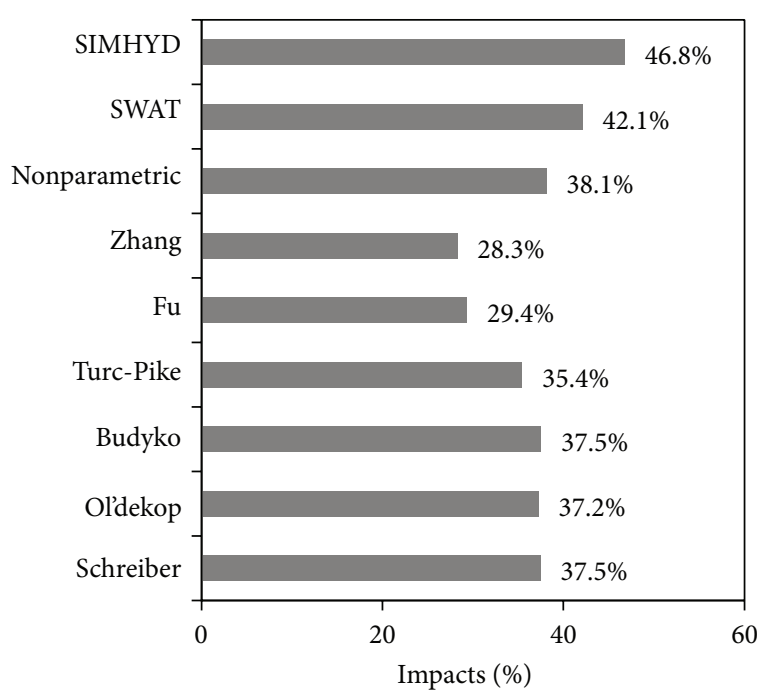

Figure 7: Comparison of impact results of change climate by the nine methods.

to the negative effects of the human activities like water diversion for irrigation and industrial and domestic water use within this basin. There are four large reservoirs in the catchment (Miaogong Reservoir (MR) in the upstream, Panjiakou Reservoir (PR) in the midstream, Daheiting Reservoir (DR) in the downstream, and Taolinkou Reservoir (TR) in the Qinglong River (a tributary of the Luan River)). Water diversion to Tianjin and Tangshan is used for industry and urban life from the PR and DR. Water is also diverted for the irrigation in the Luanxia Irrigation district from the PR, DR, and TR and in Miaogong Irrigation district from the MR following increases in the area of farmland. As a result of the economic development and the population increase, the water demand by industry, domestic usage, and irrigation has increased $[49,50]$, subsequently resulting in the decreases in streamflow in the basin. Meanwhile, the irrigation may trigger high evapotranspiration and farmers have to collect runoff to enhance crop yield, which will also reduce the runoff [46]. Furthermore, the Mann-Kendall test results of the outflow in the downstream of PR and TR show a change point around 1999. The corresponding reduction in the average annual streamflow was $43.98 \mathrm{~m}^{3} / \mathrm{s}$ and $18.73 \mathrm{~m}^{3} / \mathrm{s}$ in the PR and TR, respectively. The reductions also indicate human activities have a dominated impact on the surface runoff compared with the climate change in the LRB.

In this study, two kinds of climate elasticity methods are used to separate the effects using only the observed annual hydroclimate data. The quantitative results mainly depend on the estimation of the runoff elasticity to precipitation. From these results, the nonparametric method overestimates the reduction caused by climate change when compared with the Budyko-based methods. A possible reason may be the relatively small sample size of the historical data which leads to a relatively large error in the nonparametric method [10]. Another reason may be the reduction in runoff influenced by human activities, which lead to an overestimation of the runoff elasticity to precipitation by nonparametric method as shown in Figure 8(a), where the runoff elasticity increases with the runoff decline. Among the six Budyko-based methods, the results of the Fu and Zhang methods indicate a lower impact of climate change than the other four methods, which is also caused by the underestimation of the runoff elasticity. Figure 8(b) shows the relationship between aridity index and runoff elasticity to precipitation. From the curves in Figure $8(\mathrm{~b})$, we can see that when the aridity index is around 1.5 to 2.0 (the aridity index is 1.797 in the Luan River basin), the runoff elasticity to precipitation calculated by Zhang and $\mathrm{Fu}$ methods is smaller than that obtained by the other four methods.

The quantitative results of the two hydrological models reveal a slight difference between the models, which is mainly due to the model uncertainties. The uncertainties associated with parameter calibration are shown in Figure 9. Figure 9 shows the simulated annual runoff in the testing period, along with the $95 \%$ confidence range as obtained by the two models. We can see that the difference of simulated runoff and observed runoff ranges between $34.55 \mathrm{~mm}$ and $63.41 \mathrm{~mm}$. In the SWAT model, the contribution of human activities to the reduction in runoff was $40 \sim 70 \%$ with a mean value $55 \%$. With the SIMHYD model, the difference between simulated runoff and observed runoff varied from $23.80 \mathrm{~mm}$ to $65.60 \mathrm{~mm}$. The contribution of human activities to the reduction in runoff was $30 \sim 75 \%$ with a mean value of $53 \%$. From the uncertainty analysis, we can see that parameter calibration 


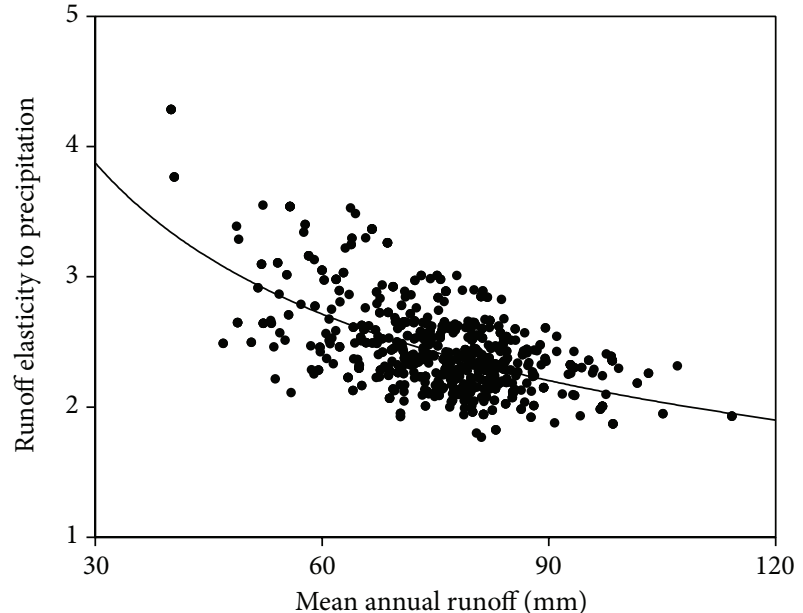

(a)

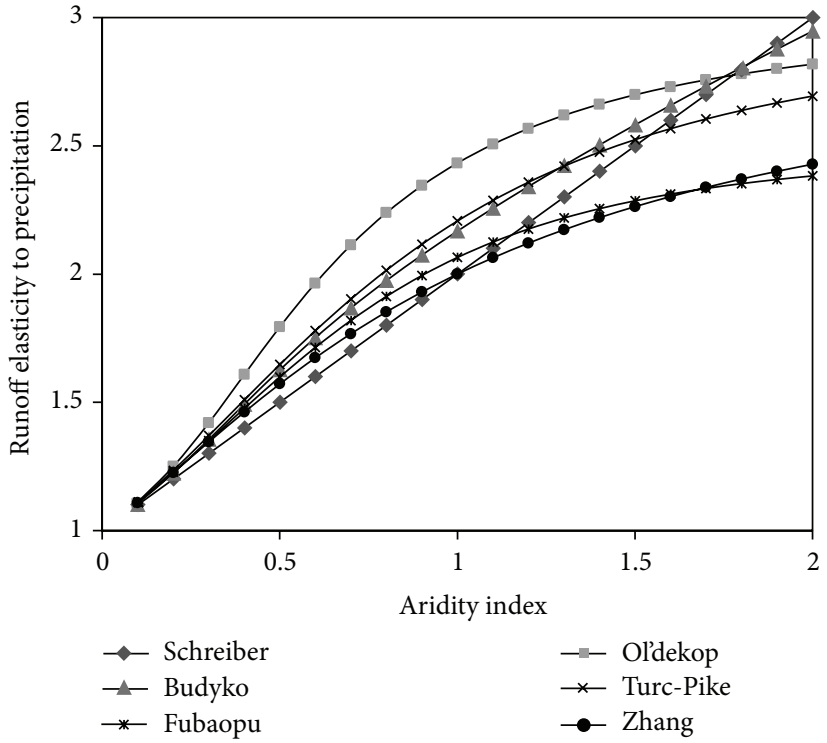

(b)

FIGURE 8: The relationship between mean annual runoff and the runoff elasticity to precipitation (a), the relationship between aridity index and the runoff elasticity to precipitation (b).
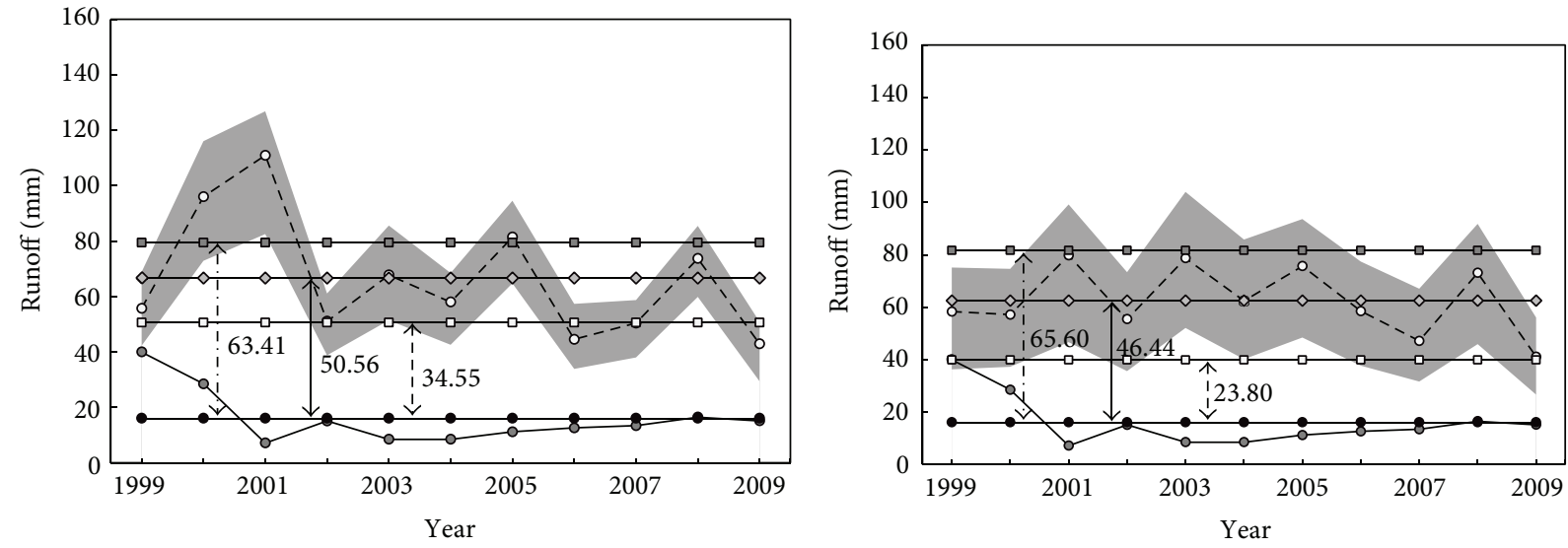

95\% confidence ranges
- - Observed runoff
$-\bigcirc-$ Simulated runoff
- Simulated mean runoff
- Observed mean runoff
$-\square$ - $95 \%$ confidence upper limit mean value
$\square-95 \%$ confidence lower limit mean value

(a)

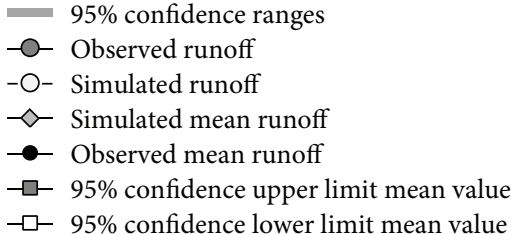

(b)

FIGURE 9: Uncertainties of the quantification results based on the SWAT (a) and SIMHYD (b) models.

may have an influence on the quantitative results. Meanwhile, we can see both the lumped SIMHYD model and the SWAT model provide useful means of quantifying the impacts, but the SIMHYD model uses fewer input datasets and is easier calibrated as described above. However, to reveal more details of the hydrological cycle, distributed hydrological models are required in the quantitative studies.

In general, both of the climate elasticity and hydrological modeling approaches have their own advantages.
The climate elasticity methods are comparatively simple with fewer inputs, while the hydrological models can simulate the water cycle with higher spatial and temporal resolution. However, there are still uncertainties associated with the results obtained by both approaches. The estimation of runoff elasticity is still a difficult problem for the climate elasticity methods, and the model uncertainties will affect the quantitative results produced by the hydrological modeling approach. Furthermore, the method used for separating the effects of 
climate change and human activities as two independent variables will also introduce uncertainties because these two factors interact with each other. For example, human activities such as urbanization may affect the energy and water fluxes back to the atmosphere which could cause changes in climate variables such as temperature and precipitation and thus changes in runoff. Meanwhile, climate change would also influence human activities such as land use and therefore subsequently cause runoff changes.

\section{Conclusions}

Here, an integrated quantitative method is successfully applied in the Luan River basin using the Budyko-based Fu model, hydrological modeling, and climate elasticity approaches. Firstly, the Budyko-based Fu model is used to explore the underlying surface characteristics of the basin. The results indicate that the change point takes place in 1999. Secondly, the hydrological modeling and climate elasticity approaches are used to separate the effects of climate change and human activities. The effect of climate change on runoff changes is about $28.3 \sim 46.8 \%$ and that of human activities accounted for about 53.2 71.7\%. The human activities including land use and cover change and water diversion for irrigation and industrial and domestic water use are considered to be responsible for the runoff decline in the basin. The results in this study could provide a scientific basis for the sustainable water resources planning and management under the influence of climate change and human activities.

In addition, the hydrological modeling approach and climate elasticity approach are compared. Climate elasticity methods are comparatively simplistic and based on fewer data, which is a good attribute for large-scale application, while the hydrological models can simulate the water cycle with higher spatial and temporal resolution. It has been proved that both approaches can effectively evaluate the influences of climate change and human activities on hydrological processes. Although the effects of climate change and human activities are successfully separated in this study, a more indepth analysis of the effects of climate variables, land use and cover change, water diversion, and other water-related human activities is needed in further work.

\section{Conflict of Interests}

The authors declare that there is no conflict of interests regarding the publication of this paper.

\section{Acknowledgments}

This study is supported by the National Basic Research Program of China ("973" Program) (2015CB452701) and National Natural Science Foundation of China (41271003).

\section{References}

[1] J. Xia, C. Z. Liu, and G. Y. Ren, "Opportunity and challenge of the climate change impact on the water resource of China," Advances in Earth Science, vol. 26, no. 1, pp. 1-12, 2011 (Chinese).
[2] G. Wang, J. Xia, and J. Che, "Quantification of effects of climate variations and human activities on runoff by a monthly water balance model: a case study of the Chaobai River basin in northern China," Water Resources Research, vol. 45, no. 7, 2009.

[3] Y. K. Zhang and K. E. Schilling, "Effects of land cover on water table, soil moisture, evapotranspiration, and groundwater recharge: a field observation and analysis," Journal of Hydrology, vol. 319, no. 1-4, pp. 328-338, 2006.

[4] J. X. Xu and J. Sun, "Influence of precipitation and human activities on water fluxes from the Yellow River into the sea in the past 50 years," Advances in Water Science, vol. 14, no. 6, pp. 690-695, 2003 (Chinese).

[5] Y. F. Zhang, D. X. Guan, C. J. Jin, A. Z.Wang, J. B. Wu, and F. H. Yuan, "Analysis of impacts of climate variability and human activity on streamflow for a river basin in Northeast China," Journal of Hydrology, vol. 410, no. 3-4, pp. 239-247, 2011.

[6] H. Y. Li, Y. Q. Zhang, J. Vaze, and B. E. Wang, "Separating effects of vegetation change and climate variability using hydrological modelling and sensitivity-based approaches," Journal of Hydrology, vol. 420-421, pp. 403-418, 2012.

[7] W. G. Wang, Q. X. Shao, T. Yang et al., "Quantitative assessment of the impact of climate variability and human activities on runoff changes: a case study in four catchments of the Haihe River basin, China," Hydrological Processes, vol. 27, no. 8, pp. 1158-1174, 2013.

[8] N. K. Tuteja, J. Vaze, J. Teng, and M. Mutendeudzi, "Partitioning the effects of pine plantations and climate variability on runoff from a large catchment in southeastern Australia," Water Resources Research, vol. 43, no. 8, Article ID W08415, 2007.

[9] Z. Bao, J. Zhang, G. Wang et al., "Attribution for decreasing streamflow of the Haihe River basin, Northern China: climate variability or human activities?" Journal of Hydrology, vol. 460461, pp. 117-129, 2012.

[10] H. X. Zheng, L. Zhang, R. Zhu, C. Liu, Y. Sato, and Y. Fukushima, "Responses of streamflow to climate and land surface change in the headwaters of the Yellow River Basin," Water Resources Research, vol. 45, no. 7, Article ID W00A19, 2009.

[11] X. Liu, C. Liu, Y. Luo, M. Zhang, and J. Xia, "Dramatic decrease in streamflow from the headwater source in the central route of China's water diversion project: climatic variation or human influence?" Journal of Geophysical Research D: Atmospheres, vol. 117, no. 6, Article ID D06113, 2012.

[12] A. Sankarasubramanian, R. M. Vogel, and J. F. Limbrunner, "Climate elasticity of streamflow in the United States," Water Resources Research, vol. 37, no. 6, pp. 1771-1781, 2001.

[13] V. K. Arora, "The use of the aridity index to assess climate change effect on annual runoff," Journal of Hydrology, vol. 265, no. 1-4, pp. 164-177, 2002.

[14] G. B. Fu, S. P. Charles, and F. H. S. Chiew, "A two-parameter climate elasticity of stream flow index to assess climate change effects on annual stream flow," Water Resources Research, vol. 43, Article ID W11419, 2007.

[15] C. Z. Liu, Z. Y. Liu, and Z. H. Xie, "Study of trend in runoff for the Haihe River Basin in recent 50 years," Quarterly Journal of Applied Meteorology, vol. 15, pp. 385-393, 2004 (Chinese).

[16] G. Z. Fan, S. H. Lü, and G. D. Cheng, "Simulation of influence of climate change on water resource over Luanhe River Valley using a hydrological model (I): introduction of precipitationrunoff modeling system (PRMS) and its replant over Luanhe River Valley," Plateau Meteorology, vol. 20, pp. 173-179, 2001 (Chinese). 
[17] Q. P. Wang and J. Y. Liu, "Analyzing the impact of climate change and human activity on the water resources change in the lower reach of Luan River," China Water Resources, no. 15, pp. 41-44, 2010 (Chinese).

[18] G. H. Hargreaves and Z. A. Samani, "Estimating potential evapotranspiration," Journal of the Irrigation \& Drainage Division, vol. 108, no. 3, pp. 223-230, 1982.

[19] X. Y. Liu, Y. Z. Li, and Q. S. Wang, "Evaluation on several temperature-based methods for estimating reference crop evapotranspiration," Transactions of the Chinese Society of Agricultural Engineering, vol. 22, no. 6, pp. 12-18, 2006 (Chinese).

[20] M. I. Budyko, Evaporation under Natural Conditions, Gidrometeorizdat, Leningrad, Russia, 1948.

[21] M. I. Budyko, Climate and Life, Academic Press, Orlando, Fla, USA, 1974.

[22] B. P. Fu, "On the calculation of the evaporation from land surface," Chinese Journal of Atmospheric Sciences, vol. 5, pp. 2331, 1981 (Chinese).

[23] F.-B. Sun, D.-W. Yang, Z.-Y. Liu, and Z.-T. Cong, "Study on coupled water-energy balance in Yellow River basin based on Budyko hypothesis," Journal of Hydraulic Engineering, vol. 38, no. 4, pp. 409-416, 2007 (Chinese).

[24] B. P. Fu, "On the calculation of the evaporation from land surface in mountainous area," Scientia Meteorologica Sinica, vol. 16, pp. 328-335, 1996 (Chinese).

[25] P. C. D. Milly, "Climate, soil water storage, and the average annual water balance," Water Resources Research, vol. 30, no. 7, pp. 2143-2156, 1994.

[26] M. T. Hobbins, J. A. Ramírez, and T. C. Brown, “The complementary relationship in estimation of regional evapotranspiration: an enhanced advection-aridity model," Water Resources Research, vol. 37, no. 5, pp. 1389-1403, 2001.

[27] H. B. Mann, "Nonparametric tests against trend," Econometrica, vol. 13, pp. 245-259, 1945.

[28] M. G. Kendall, Rank Correlation Methods, Griffin, London, UK, 1975.

[29] F. H. S. Chiew, M. C. Peel, and A. W. Western, "Application and testing of the simple rainfall-runoff model SIMHYD," in Mathematical Models of Small Watershed Hydrology and Application, V. P. Singh and D. Frevert, Eds., pp. 335-367, Water Resource Publications, Littleton, Colo, USA, 2002.

[30] G. Q. Wang, J. Y. Zhang, R. M. He, N. Q. Jiang, and X. A. Jing, "Runoff reduction due to environmental changes in the Sanchuanhe river basin," International Journal of Sediment Research, vol. 23, no. 2, pp. 174-180, 2008.

[31] P. W. Gassman, M. R. Reyes, C. H. Green, and J. G. Arnold, "The soil and water assessment tool: historical development, applications, and future research directions," Transactions of the $A S A B E$, vol. 50, no. 4, pp. 1211-1250, 2007.

[32] L. P. Zhang, S. D. Zeng, R. C. Wang, and J. Xia, "Impacts of climate change on the hydrological cycle in the Luan River Basin," Resources Science, vol. 33, no. 5, pp. 966-974, 2011.

[33] Q. Y. Duan, S. Sorooshian, and V. Gupta, "Effective and efficient global optimization for conceptual rainfall- runoff models," Water Resources Research, vol. 28, no. 4, pp. 1015-1031, 1992.

[34] J. E. Nash and J. V. Sutcliffe, "River flow forecasting through conceptual models, part I-a discussion of principles," Journal of Hydrology, vol. 10, no. 3, pp. 282-290, 1970.

[35] J. C. Schaake, "From climate to flow," in Climate Change and U.S. Water Resources, P. E. Waggoner, Ed., chapter 8, pp. 177206, John Wiley \& Sons, New York, NY, USA, 1990.
[36] P. Schreiber, "Über die Beziehungen zwischen dem Niederschlag und der Wasserführung der Flüße in Mitteleuropa," Zeitschrift für Meteorologie, vol. 21, pp. 441-452, 1904.

[37] E. M. Ol'dekop, "On evaporation from the surface of river basins," Transactions on Meteorological Observations, University of Tartu, vol. 4, p. 200, 1911.

[38] J. G. Pike, "The estimation of annual run-off from meteorological data in a tropical climate," Journal of Hydrology, vol. 2, no. 2, pp. 116-123, 1964.

[39] L. Zhang, W. R. Dawes, and G. R. Walker, "Response of mean annual evapotranspiration to vegetation changes at catchment scale," Water Resources Research, vol. 37, no. 3, pp. 701-708, 2001.

[40] L. J. Li, L. Zhang, H. Wang et al., "Assessing the impact of climate variability and human activities on streamflow from the Wuding River basin in China," Hydrological Processes, vol. 21, no. 25, pp. 3485-3491, 2007.

[41] J. C. I. Dooge, M. Bruen, and B. Parmentier, "A simple model for estimating the sensitivity of runoff to long-term changes in precipitation without a change in vegetation," Advances in Water Resources, vol. 23, no. 2, pp. 153-163, 1999.

[42] H. Yang and D. Yang, "Derivation of climate elasticity of runoff to assess the effects of climate change on annual runoff," Water Resources Research, vol. 47, no. 7, Article ID W07526, 2011.

[43] X. Xu and D. Yang, "Analysis of catchment evapotranspiration at different scales using bottom-up and top-down approaches," Frontiers of Architecture and Civil Engineering in China, vol. 4, no. 1, pp. 65-77, 2010.

[44] S. Yue and C. Y. Wang, "Applicability of prewhitening to eliminate the influence of serial correlation on the MannKendall test," Water Resources Research, vol. 38, Article ID W00A11, 2002.

[45] S. R. Zhang and X. X. Lu, "Hydrological responses to precipitation variation and diverse human activities in a mountainous tributary of the lower Xijiang, China," Catena, vol. 77, no. 2, pp. 130-142, 2009.

[46] Y. H. Yang and F. Tian, "Abrupt change of runoff and its major driving factors in Haihe River Catchment, China," Journal of Hydrology, vol. 374, no. 3-4, pp. 373-383, 2009.

[47] E. D. Hetherington, "The importance of forests in the hydrological regime," in Canadian Bulletin Fisheries and Aquatic Sciences, M. D. Healy and R. R. Wallace, Eds., no. 215, p. 533, Department of Fisheries and Oceans, Ottawa, Canada, 1987.

[48] J. D. Stednick, "Monitoring the effects of timber harvest on annual water yield," Journal of Hydrology, vol. 176, no. 1-4, pp. 79-95, 1996.

[49] X. Zhu, W. Cao, and Y. Zhang, "Water resources analysis in Haihe river catchment," Water Resources, vol. 6, pp. 6-8, 2007 (Chinese).

[50] B. Y. Yang, "Reason analysis of runoff reduction in Nanzhuang station of Hutuohe River Basin," Shanxi Water Resources, vol. 6, pp. 34-35, 2007 (Chinese). 

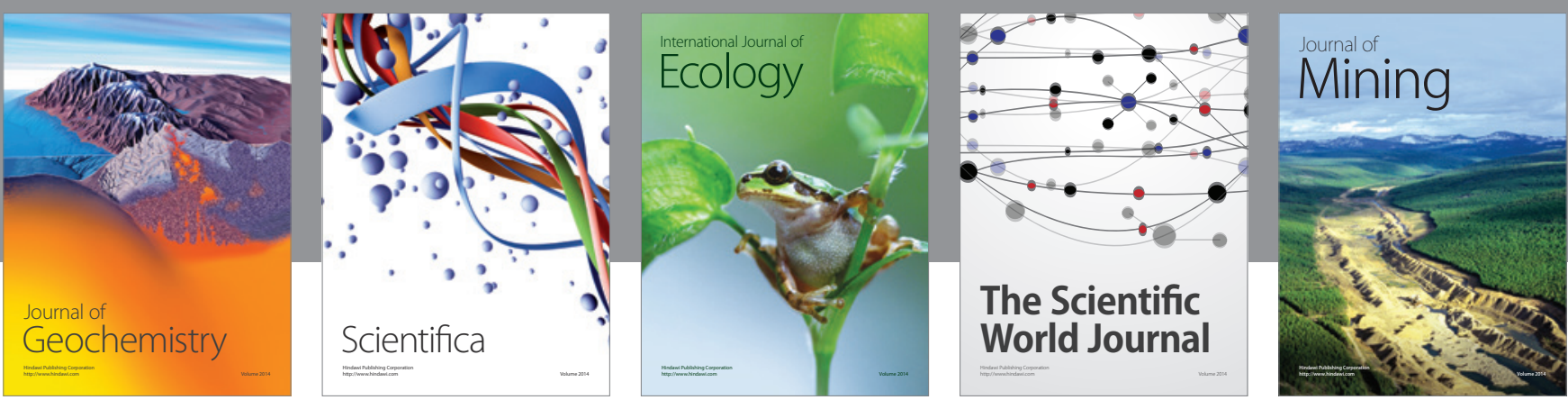

The Scientific World Journal
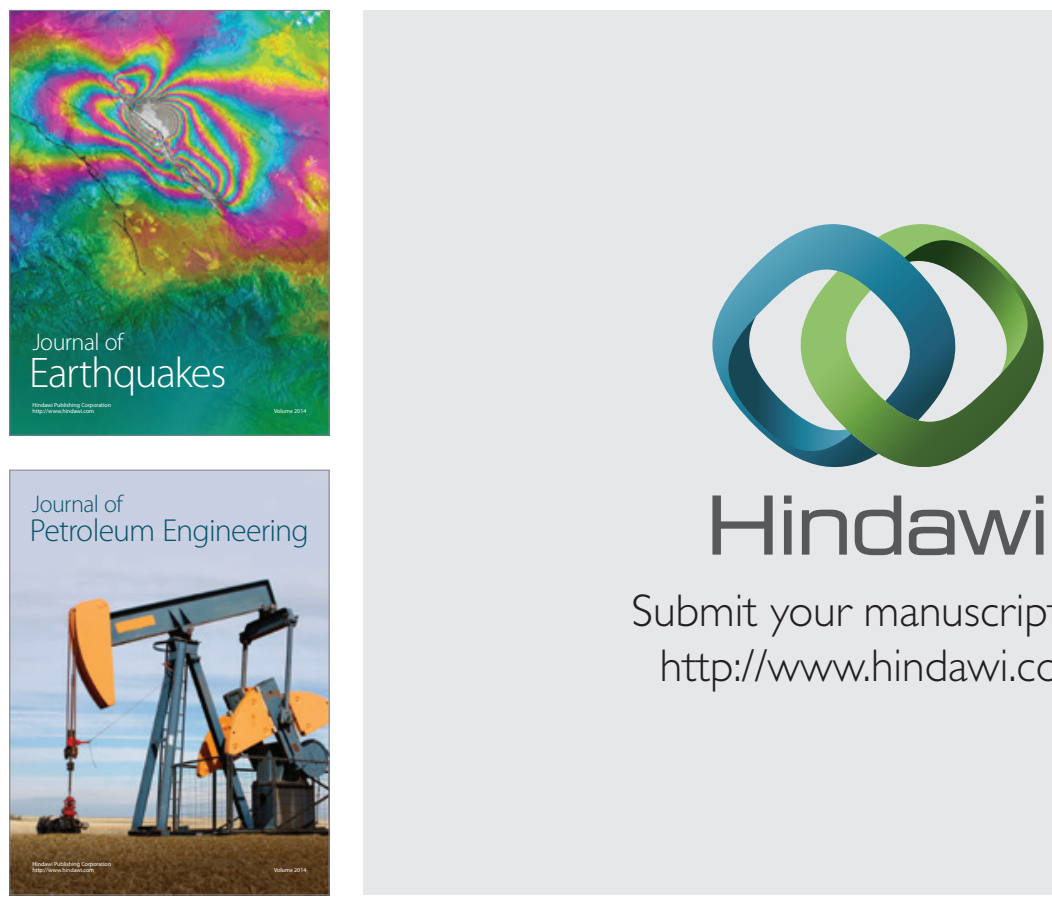

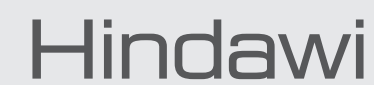

Submit your manuscripts at

http://www.hindawi.com
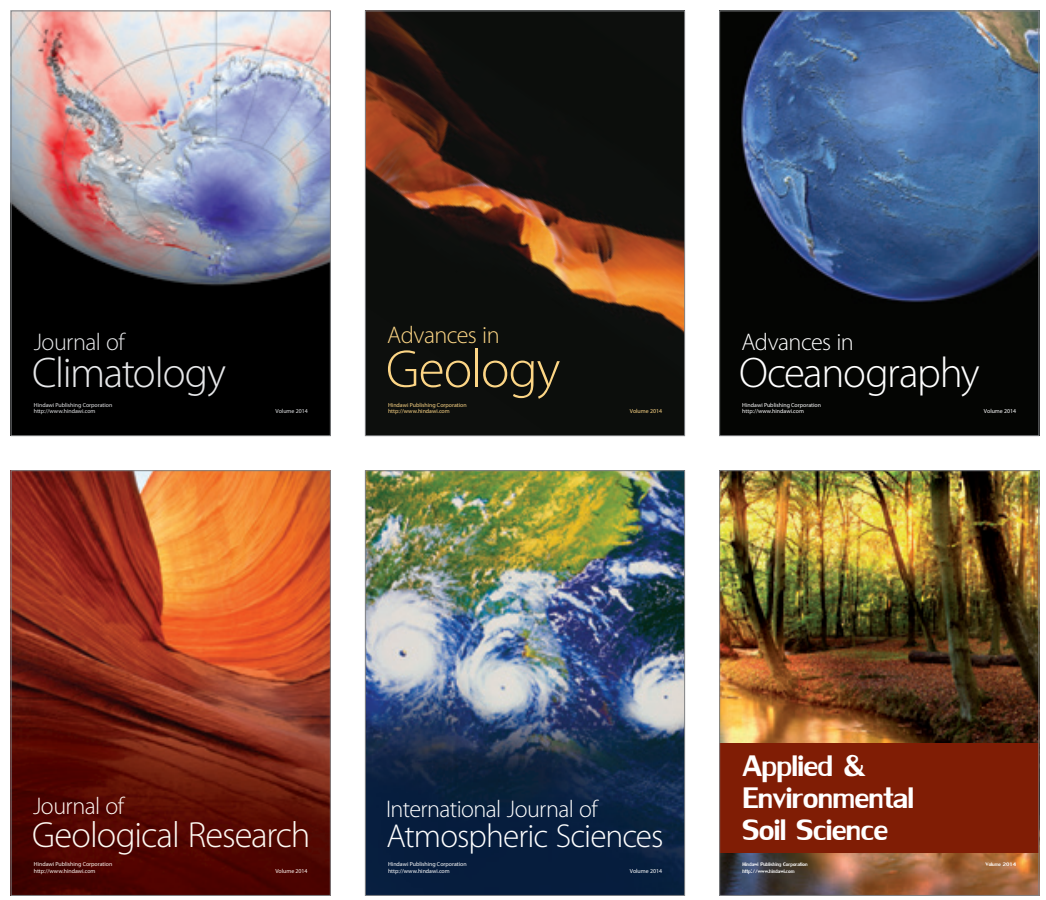
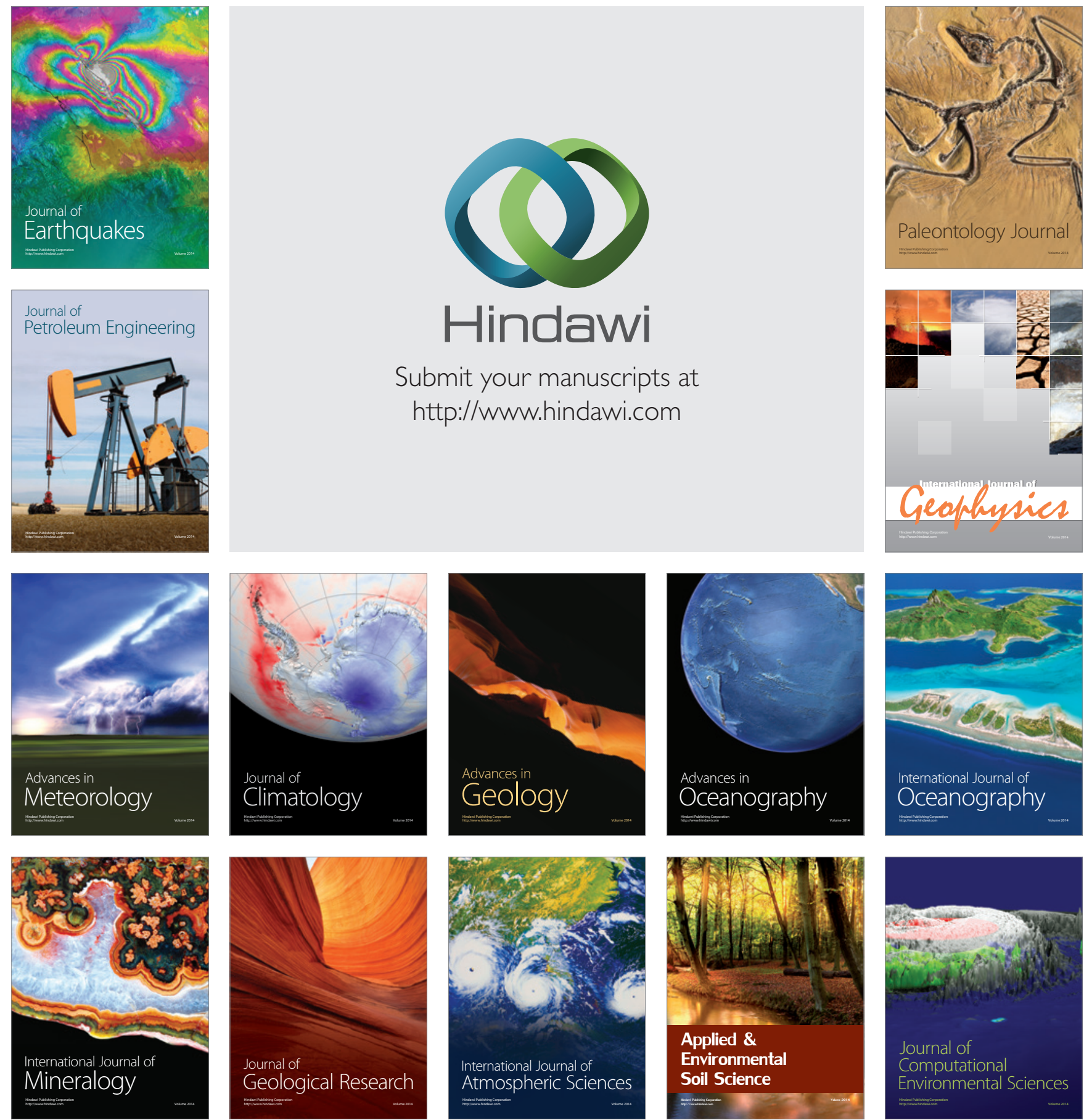